\title{
Addiction training for undergraduate nurses using screening, brief intervention, and referral to treatment
}

\author{
Helen K. Burns ${ }^{1}$, Kathryn R. Puskar², Michael T. Flaherty ${ }^{3}$, Ann M. Mitchell ${ }^{2}$, Holly Hagle ${ }^{3}$, Betty \\ Braxter $^{2}$, Marie Fioravanti ${ }^{2}$, Heather J. Gotham ${ }^{4}$, I rene Kane ${ }^{2}$, Kimberly S. Talcott ${ }^{2}$, Lauren \\ Terhorst $^{2}$, Gail R. Woomer ${ }^{2}$
}

1. Excela Health, Latrobe, PA, USA. 2. School of Nursing, University of Pittsburgh, Pittsburgh, USA. 3. Institute for Research, Education \& Training in Addictions, Pittsburgh, PA, USA. 4. University of Missouri, Kansas City, MO, USA.

Correspondence: Kathryn R. Puskar. Address: School of Nursing, University of Pittsburgh. 3500 Victoria Street, 415 VICTO. Pittsburgh, PA 15261. Telephone: 412-624-6933. Fax: 412-383-7293. E-mail: Krp12@pitt.edu

Received: January 10, 2012

DOI : 10.5430/jnep.v2n4p167
Accepted: March 21, $2012 \quad$ Published: November 1, 2012

URL: http://dx.doi.org/10.5430/jnep.v2n4p167

\begin{abstract}
Background: An academic-community partnership was created to integrate education and training on the evidence-based practice of Screening, Brief Intervention and Referral to Treatment (SBIRT) for substance use into the undergraduate nursing curriculum at a major research university. The purpose of this paper is to: 1) describe an 11-module addictions training program created through an academic-community partnership; and 2) discuss curriculum implications for other schools of nursing.

Methods: A case study presents the collaboration between a school of nursing and a nonprofit agency specializing in addictions that created substance use training materials and skill-building exercises specifically for undergraduate nurses.

Results: The 11-module addictions training curriculum component lasted 13 total hours and was incorporated into the 15-week Psychiatric Mental Health Nursing course and clinical rotations. The evidence-based addictions training model was successfully provided to 392 undergraduate nurses and 39 instructors.

Discussion: Schools of nursing and other health agencies can utilize the substance use screening and brief intervention curriculum. By raising nursing students' awareness about the prevalence of harmful substance use, the academiccommunity partnership helped to deconstruct the stereotypes and stigma associated substance use, abuse, and addiction.
\end{abstract}

\section{Key words}

Addictions training, Undergraduate nursing curriculum, Screening, Brief intervention, Referral to treatment

\section{I ntroduction}

Schools of nursing are charged with preparing student nurses for multiple increasingly challenging practices. One area of health care challenge and change is patients' increased use and abuse of substances. The prevalence of patients with alcohol and/or other drug problems is very high. In a six state study in which screening for alcohol and drug issues was implemented across healthcare settings, $22.7 \%$ of patients screened positive for a range of alcohol and drug use issues 
from risky or problematic use to substance abuse or dependence ${ }^{[1]}$. Of all general hospital admissions, $25 \%$ involve complications related to substance use ${ }^{[2]}$. Nurses working in any clinical setting will care for patients using substances ${ }^{[3]}$. Thus, nurses need relevant training to prepare them to identify and meet the needs of those patients who misuse substances ${ }^{[2,4]}$.

Responses to changes in academia tend to happen very slowly creating a challenge to keep pace with changing clinical realities ${ }^{[5]}$. Graduating nurses then encounter changing health needs in practice, perhaps causing undue stress and burnout. Professional nursing organizations recognize that a key aspect of mitigating the nursing shortage relies on nursing education that meets the "general and specialized healthcare needs of society" [6].

Research suggests that healthcare workers who implement evidence-based practices that help them to better address patient needs find their jobs more rewarding and less taxing, and remain at their jobs longer ${ }^{[7]}$. Educational programs that increase students' 'readiness to practice,' including enhancing clinical skill-building opportunities and building cultural competence in care ${ }^{[8]}$, help ease the transition to the workforce and reduce turnover ${ }^{[9]}$.

Despite the prevalence of substance use and misuse in the patient population, addictions education in the nursing curricula is lacking ${ }^{[10]}$ and may be less than the drug and alcohol education provided in medical and other health professional schools ${ }^{[11]}$. A large portion of nursing educational efforts have been unilateral, i.e., nursing leaders have not strategically used the advantages afforded by partnering with community organizations to improve and sustain educational opportunities ${ }^{[12]}$.

Through collaborative efforts between a large, nationally prominent, research-focused university school of nursing and a small nonprofit agency that focuses on research, education, and training in addictions, an innovative addictions curriculum component was developed and incorporated into the nursing curriculum. The resulting partnership is an example of a unique collaboration that addressed changing clinical needs leading to effective nursing practice.

The purpose of this paper is to: 1 . Describe an 11-module addictions training program created through an academiccommunity partnership; and 2 . Discuss implications for other schools of nursing.

\section{Background}

The lack of substance abuse information and skill development opportunities in nursing student education is one of the many factors contributing to the substance use "treatment gap". This refers to the 20.5 million individuals age 12 and older (approximately 7\% of the population) who were identified as needing treatment for alcohol and/or drug problems but did not receive services ${ }^{[13]}$. Of those identified by healthcare professionals as needing treatment, only 1 in 20 perceived themselves as needing treatment for their substance use ${ }^{[13]}$. Moreover, another 68 million Americans have risky or 'unhealthy use' of alcohol and drugs ${ }^{[14]}$.

In 2001, a report by the Schneider Institute for Health Policy at Brandeis University ${ }^{[15]}$ characterized substance use disorders (alcohol and drug abuse and dependence) as the "nation's number one health problem". Substance use is still reported as "one of today's most pressing public health concerns" ${ }^{[16]}$. The World Health Organization reports that worldwide use of alcohol is responsible for almost 13 disability-adjusted life years lost per 1,000 in population, and drug use accounts for approximately two days lost ${ }^{[17]}$.

Substance abuse and dependence lead to substantial costs for society. This health problem costs society more than \$275 billion per year, largely from associated medical and criminal justice costs ${ }^{[15]}$. It has long been recognized that alcohol use is a leading cause of disability among males age 15-44 and the 5th leading overall cause of disability ${ }^{[18]}$. Substance use also has a profound impact on youth and the child welfare system. Maternal alcoholism and other substance use disorders are one of the leading risk factors for poor school performance and behavioral problems ${ }^{[19]}$. The majority of children who are reported to the child welfare system for maltreatment have experienced a number of known risk factors, one of which 168

ISSN 1925-4040 E-ISSN 1925-4059 
is parental substance use problems ${ }^{[20]}$. Additionally, substance use remains a strong contributing factor to involvement in the criminal justice system. Half of federal inmates (50\%) report using drugs in the month before their arrest ${ }^{[21]}$.

An individual's abuse of substances can go undetected or unacknowledged for years, thereby undermining an individual's health and well-being ${ }^{[22]}$. Healthy People 2020 cites emerging issues in substance abuse such as adolescent abuse of prescription drugs and military operations placing a strain on military personnel and their families ${ }^{[23]}$.

As early as 1990, the Institute of Medicine recognized the need for health provider-initiated screening to identify alcohol abuse, dependence and associated problems ${ }^{[24]}$. This call led to widespread support for the use of screening, brief intervention, and referral to treatment (SBIRT) in general health care settings (e.g., ERs, primary care settings, health clinics). Bernstein ${ }^{[25,26]}$ implemented an SBIRT curriculum for emergency care professionals and found it to be effective. Screening by health professionals has been associated with reductions in alcohol use, health care utilization, criminal justice involvement, and societal costs ${ }^{[27-33]}$. Benefits of brief intervention have been observed in follow-up studies three to nine years post-intervention ${ }^{[31,34-37]}$.

SBIRT is "a comprehensive, integrated, public health approach to the delivery of early intervention and treatment services for persons with substance use disorders, as well as those who are at risk of developing these disorders". ${ }^{[38]}$. By engaging with patients earlier along the continuum of substance use and abuse, nurses have an opportunity to intervene with patients who are at-risk for engaging in increasingly dangerous behavior. SBIRT involves screening to assess the patient for substance use, brief intervention using motivational interviewing to educate the patient and move toward behavior change, identification of the suitable level of treatment, and referral to treatment if the patient needs specialty care ${ }^{[38]}$.

SBIRT is congruent with the Substance Abuse Objectives in Healthy People 2020. Each of the 21 Substance Abuse (SA) Objectives call for risk reduction. One objective specifically advocates for increases in referrals for follow-up care after diagnosis of a substance use problem (SA-9). Objective SA-10 is directly applicable to SBIRT through "Increas(ing) the number of Level I and Level II trauma centers and primary care settings that implement evidence-based alcohol Screening and Brief Intervention” ${ }^{[23]}$.

Generalist nurses are an important element in the implementation of alcohol use identification, prevention, and intervention ${ }^{[39]}$. While emphasis is often placed on the need for more specialty substance use disorder clinicians to alleviate the treatment gap and increase system capacity ${ }^{[5]}$, increased capacity by nurses would assist in addressing substance use-related problems before they require specialty treatment. Nurses are an ideal provider of SBIRT because of their practice role, amount of time spent with patients compared to other health practitioners, and the nursing skill set which includes health promotion, patient education and interpersonal communication ${ }^{[40]}$.

\section{Method: Case Study}

\section{Creation of an Academic-Community Partnership and the Development of an Addictions Training Curriculum}

The partnership between the two organizations was crucial to transforming the evidence-based practice of SBIRT into a component of an undergraduate nursing curriculum. The balanced nature of the partnership, that each organization was strong in a different area and each could contribute to the partnership ${ }^{[41]}$, made the development and implementation of the addictions curricular enhancement successful. In this case, the University of Pittsburgh School of Nursing brought a willingness to better prepare their undergraduate nurses for practice upon graduation and an ideal setting in which to implement an evidence-based practice. The Institute for Research, Education \& Training in Addictions (IRETA) brought expertise in addictions teaching, training, and evaluation.

The University of Pittsburgh is a comprehensive education and research institution. The School of Nursing is one of six health science schools within the University. With a vision of 'Advancing Nursing Science, Education and Practice,' the Published by Sciedu Press 
School of Nursing offers programs leading to the BSN (first-degree, second-degree, and RN-BSN), MSN (Nurse Practitioner, Clinical Nurse Specialist, Nurse Anesthesia and Advanced Specialty Roles as first master's, second master's, and RN-MSN), Doctor of Nursing Practice (DNP), and PhD, including the BSN-PhD track. The School of Nursing educates approximately 600 undergraduate students at any point in time.

IRETA is a 501(c) (3) with the vision to integrate knowledge and science with service to assure that every person has an opportunity to achieve wellness and maintain recovery from addiction. To achieve its mission to improve the recognition, prevention, treatment, research and policy related to addictions and recovery, IRETA works with national, state, and local partners in providing: 1) accurate and timely dissemination of evidence-based information; 2) bidirectional exchange of constructive knowledge related to addiction and recovery; and 3) knowledge of addiction and recovery in a culturally competent manner. IRETA advocates for the consistent use of evidence-based practices and supports policies of care which treat addiction as a chronic illness by seeking to eliminate the stigma related to addiction. IRETA is the administrator of a federally funded Addiction Technology Transfer Center regional center.

To increase the number of nursing professionals in the workforce prepared to address the needs of at-risk users of alcohol and other drugs, the project partners designed an addiction training educational component to be integrated into the existing School of Nursing curriculum. The School of Nursing and IRETA began their partnership in fall 2006 with pilot implementation of a 3-hour addictions seminar. The pilot was expanded into the Addiction Training for Nurses using Screening, Brief Intervention and Referral to Treatment (ATN-SBIRT) Program. The project applied for and received support from the United States Department of Health and Human Services (DHHS), Health Resources and Services Administration (HRSA), as part of the Nurse Education, Practice, and Retention (NEPR) program (Grant award number D11HP14629).

Unique in both concept and delivery, the 11-module, 13-hour ATN-SBIRT Curriculum Design (see Figure 1) is proactive in its education of undergraduate nursing students. Prior to the project partnership, IRETA established a strong reputation in the quality training of certified, direct service professionals already working in their field of practice. Uniquely, the ATN-SBIRT Project provides similar education and training to pre-professional nursing students, therefore contributing to students' 'readiness to practice' upon graduating and entering the workforce.

Overview: This 11-module course was developed to educate undergraduate nursing students or professional nurses in basic information about substance use disorders and application of knowledge of substance use disorders to the clinical practice of nursing including practice in screening, assessment and brief intervention for the identification of use, misuse or dependency of drugs and alcohol.

Goal: Nurses will be able to identify and help patients with drug and alcohol use, misuse and dependency.

Objectives:

1) Understand basic issues around alcohol and other drugs as they relate to the continuum of use, abuse and dependency.

2) Consider the principles of screening, assessment and brief intervention and the engagement of the patient in the stages of change.

3) Recognize the stages of change and their implication for the intervention process.

4) Develop skills in the utilization of screening and brief intervention and positive approaches to dealing with patients using alcohol and other drugs based on patients' current readiness for change.

Methods of Instruction: Lecture, facilitated discussion, group and individual activities, pre-session readings and assignments.

Figure 1. Addiction Training for Nurses using Screening, Brief Intervention, and Referral to Treatment (ATN-SBIRT) Curriculum Design

The integration of the project into the School of Nursing undergraduate curriculum allowed for the natural placement of the training within the framework of an already-established 15-week Psychiatric Mental Health Nursing course. The 11-module curriculum component includes eight hours of in-classroom education and training sessions capitalizing on the rigor of standard School of Nursing classroom learning activities while providing specified time for in-depth and hands-on 
training in the student schedule. The evidence-based practice educational component was supported by three hours of skill-development opportunities at clinical sites and two hours of culturally relevant simulation laboratory case scenarios. The simulation lab provided students the opportunity to develop their skills in delivering culturally appropriate care to diverse populations.

The ATN-SBIRT Curriculum is based on the "Understanding Addiction" and "Treatment Knowledge" standards and competencies outlined in the Substance Abuse and Mental Health Services Administration (SAMHSA) Center for Substance Abuse Treatment's Addiction Counselor Competencies ${ }^{[42]}$. Derived from the educational materials IRETA created as the training entity for the Commonwealth of Pennsylvania's SBIRT grant (2003-2008), the ATN-SBIRT Curriculum was developed with the aim of educating pre-professional nurses using the Scope and Standards of Addictions Nursing Practice ${ }^{[43]}$. For this specific training population, the project partners incorporated video scenarios and case studies from the clinical practice environment with a nursing perspective, nursing specific statistics, and identification of and support for the impaired nurse professional. The result was a comprehensive, replicable ATN-SBIRT Curriculum design. Table 1 illustrates the list of the 11 module topics which include: an overview of substance use disorders, the pathophysiology of addiction, barriers to treatment, the specifics of SBIRT, referral and treatment issues, culturally appropriate care, and the impaired professional.

The ATN-SBIRT Curriculum is different in content and number of modules when compared with the to-be-released online curriculum created by the National Institute on Alcohol Abuse and Alcoholism (NIAAA). The NIAAA curriculum is 9 modules focusing specifically on alcohol use disorders ${ }^{[44]}$. The ATN-SBIRT curriculum has 11 modules providing content on both alcohol and drug use.

A review of the Addictions Nursing Core Curriculum, an excellent contribution to the field of additions nursing developed by the International Nurses Society on Addictions (IntNSA), was conducted ${ }^{[45]}$. The 2006 edition includes seven chapters: specialty of addictions nursing, theoretical perspectives, neurobiology of addiction, health promotion and risk reduction, diagnosing and treatment, recovery and change, and special populations. The ATN-SBIRT curriculum content specifically differs from both the NIAAA and the IntNSA curriculums through presentation of information about the identification, intervention, treatment and monitoring of the impaired nurse/healthcare professional.

After development and pilot testing of the ATN-SBIRT Curriculum, the project partners established a work plan to ensure successful integration of the ATN-SBIRT Curriculum into the established School of Nursing undergraduate curriculum. Intentional planning increases the chances of a successful partnership ${ }^{[12]}$. The University School of Nursing and IRETA based the curriculum integration project development on best practices in technology transfer ${ }^{[46]}$ and Social Learning Theory ${ }^{[47]}$.

Simpson ${ }^{[48]}$ describes a four-stage framework for effective Technology Transfer. The first stage, "exposure,” usually occurs through lecture, self-study, or other similar methods. The second stage, "adoption," refers to the formal decision made by leadership to incorporate an innovation. In the third stage, "implementation," the individuals test the feasibility and potential of the innovation through practical use. The fourth and last stage is "practice" in which the innovation is incorporated into routine use. Specific activities and structures such as follow-up training, observation/feedback, technical assistance, and an integrated continuous quality improvement plan are among the most effective methods for transferring innovations to practice ${ }^{[49-51]}$.

In addition to best practices in technology transfer, Bandura's ${ }^{[47]}$ Social Learning Theory, specifically the concept of observational learning, informed the design of the project's clinical activities. Reinforcement of knowledge and skills greatly increases the likelihood that any innovation will be adopted ${ }^{[47]}$. Social learning theory has been useful as a foundation for nursing educational efforts ${ }^{[52]}$, and many studies show the effectiveness of observational learning in adoption of new behaviors ${ }^{[33-55]}$. Because clinical training in addictions is "a particularly neglected area" of alcohol and drug education in schools of nursing ${ }^{[11]}$, students practiced their new skills in the clinical setting. Each week the Published by Sciedu Press 
junior-level students completed an 8-hour day of rotations in medical-surgical, psychiatric mental health, obstetrics, geriatrics, and community health clinical sites. At each site, students were supervised by trained clinical instructors while screening and assessing patients for harmful substance use. The students then provided supervised care based on screening results.

Figure 2 (Partnership Structure) shows the collaboration between the School of Nursing and IRETA by illustrating the specific activities and steps related to the curriculum integration. The core of Figure 2 outlines the School of Nursing's activities while the outer rim describes the actions of IRETA. There were four stages to the curricular implementation which are: 1. Train the Trainers; 2. Teach the Students; 3. On-Site Clinical Rotations; and 4. Continuous Quality Improvement for Evaluation.

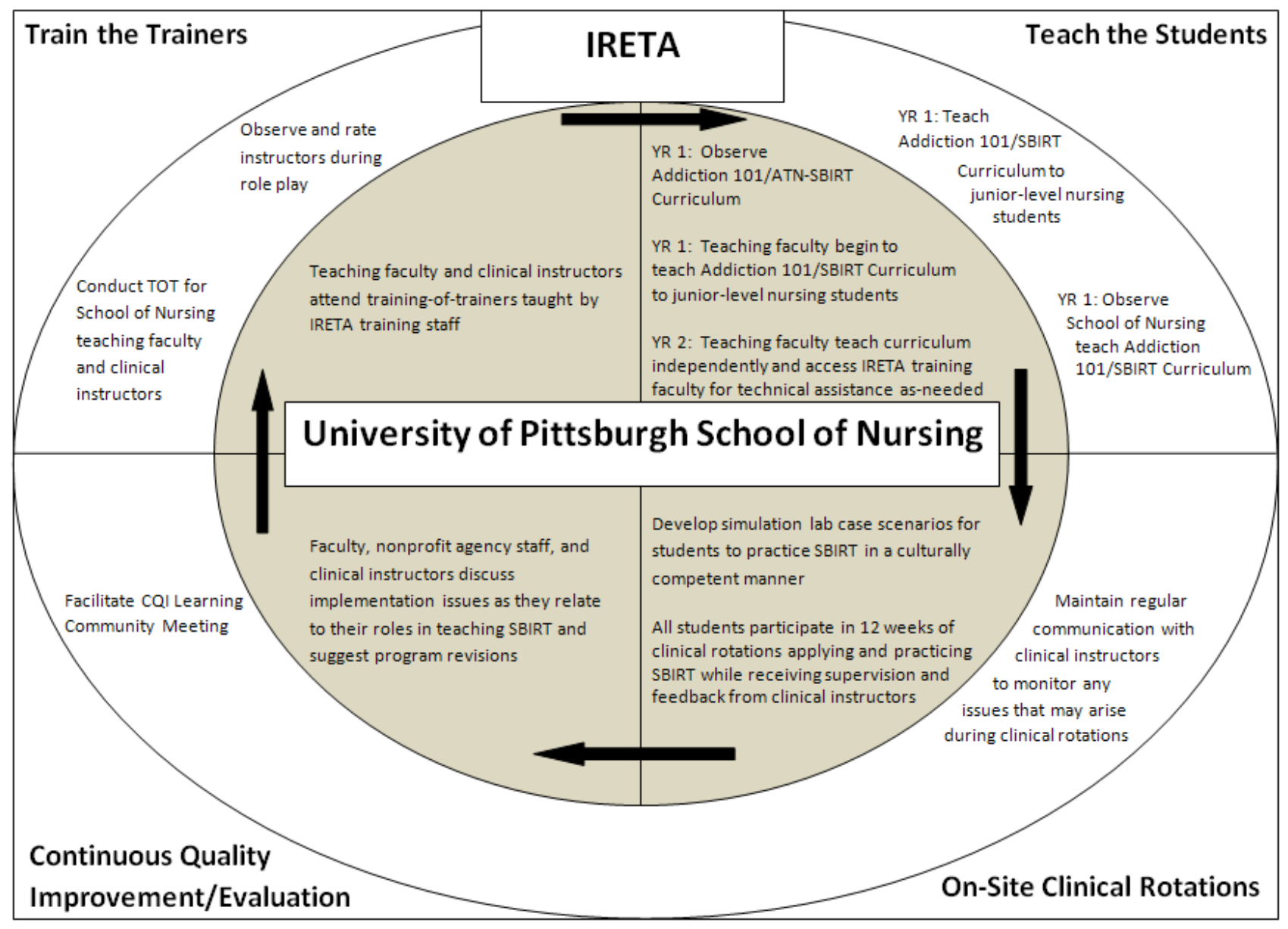

Figure 2. Partnership Structure

\section{Stage 1: Train the Trainers}

The first stage of Simpson’s ${ }^{[48]}$ Technology Transfer Framework, "exposure”, began in the "Train the Trainers” quadrant of Figure 2. School of Nursing teaching faculty, clinical instructors and clinical preceptors participated in Training-of-Trainers (ToT) sessions over the course of a year and a half. Each session included an overview of the evidence-based practice and an overview of the ATN-SBIRT Program. Additionally, faculty and clinical preceptors participated in a webinar training to review curriculum goals, objectives and evaluation components. After the ToT, School of Nursing teaching faculty observed IRETA teach the ATN-SBIRT Curriculum (see Table 1) to junior-level nursing students, thereby addressing Simpson's ${ }^{[48]}$ “adoption” and “implementation” stages of Technology Transfer. 
Table 1. ATN-SBIRT Curriculum

\begin{tabular}{ll}
\hline Module & Title \\
\hline 1 & Characteristics and Overview of Substance Abuse Disorders \\
2 & Pathophysiology of Addiction \\
3 & Treatment Issues \\
4 & Barriers To Treatment \\
5 & Identification: Signs and Symptoms \\
6 & Assessments Overview \\
7 & SBIRT (Screening, Brief Intervention and Referral to Treatment) \\
8 & Treatment Approaches \\
9 & Culturally Appropriate Care \\
10 & Impaired Professional \\
11 & Demonstration of Knowledge and Skills for the Identification of Use, Misuse, and Dependence of \\
\hline
\end{tabular}

\section{Stage 2: Teach the Students}

After the teaching faculty and clinical preceptors were trained and observed IRETA teach the ATN-SBIRT Curriculum, the project moved from "implementation" to "practice" in Simpson's ${ }^{[48]}$ framework. This stage of the partnership is illustrated by the "Teach the Students" quadrant of Figure 2. The ATN-SBIRT Curriculum was taught during the spring and fall semesters to junior nursing students along with a review-and-update session in the senior year. The 11-module ATN-SBIRT Curriculum (see Table 1) involved eight hours of educating undergraduate nursing students in basic information about substance use disorders and five hours in the application of that knowledge to clinical nursing practice (two hours in simulation, three hours in clinical rotations) integrating Bandura's ${ }^{[47]}$ observational learning concept. Through the education and training provided in the ATN-SBIRT Curriculum, undergraduate nursing students practiced the evidence-based SBIRT model in the classroom via role-play and directly with patients during clinical rotations.

\section{Stage 3: On-Site Clinical Rotations}

The "On-Site Clinical Rotations” quadrant of Figure 2 outlines the plan to provide the nursing students an opportunity to practice their new skills directly with patients in their clinical rotations while receiving supervision and feedback from clinical supervisors. The clinical rotations were conducted in psychiatric mental health, medical-surgical, obstetrics, geriatrics, and community health settings. IRETA maintained regular communication with clinical instructors throughout the project to monitor any issues that arose during clinical rotations. To ensure all students were able to practice the evidence-based model in a culturally competent manner, simulation lab case scenarios were created based on Standard 1: Assessment of the Scope and Standards of Practice for Psychiatric Mental Health Nursing Practice ${ }^{[56]}$ and Standard 1: Assessment of the Scope and Standards of Addictions Nursing Practice ${ }^{[44]}$. The simulation lab added an additional site to the students' clinical rotation schedule and ensured all students encountered diverse situations they may not otherwise have had the opportunity to experience during their clinical rotations. The nursing students' clinical rotations further address Simpson's [48] "practice" stage of Technology Transfer and also incorporate the ideas of Social Learning Theory through the reinforcement of skills learned in the classroom.

\section{Stage 4: Continuous Quality Improvement/Evaluation}

At the end of each academic term, IRETA staff and School of Nursing program faculty attended a learning community meeting as illustrated by the "Continuous Quality Improvement/Evaluation” quadrant in Figure 2. Faculty, nonprofit 
agency staff, and clinical instructors had the opportunity to discuss implementation issues related to their roles in teaching the evidence-based practice and to offer suggestions for program and implementation revisions.

\section{Results}

The partnership effectively established an educational and skill-building program for nursing students in the School of Nursing. The ATN-SBIRT Curriculum was well received by faculty, preceptors and students. To date, 392 BSN students and 39 instructors have been trained. The academic-community partnership and ATN-SBIRT Curriculum raised awareness about the prevalence of addictions in numerous healthcare settings, helped to deconstruct stereotypes and stigma associated with addiction, facilitated linkages between fragmented healthcare and community sectors, and better equipped future nurses to identify, assess, and provide care to the underserved and high risk population of those who use and misuse alcohol and other drugs. Results of the project have been disseminated through oral and poster presentations. As a result of the three-year project, a 1.5 hour Addictions Training Online Module was developed and made available for international dissemination with continuing education units for any nurse or healthcare professional. See website for additional information and registration: http://nursing.pitt.edu/academics/ce/SBIRT.jsp. The online module was well received by faculty and other nurses.

\section{Discussion}

Partnerships must be created and nurtured within both nursing education and care delivery systems to create a skilled and abundant nursing workforce ${ }^{[12]}$. Key aspects that contributed to the partnership's success included balanced contributing organizations each bringing mutually beneficial needs and solutions; a committed project team of trainers, administrators, and teaching faculty; and pre-determined quality improvement activities leading to a sound curriculum enhancement for nursing students. Through integration of the model throughout the undergraduate curriculum including numerous specialty areas (e.g. psychiatric mental health, medical-surgical, obstetrics and gynecology, geriatrics, and community health), the ATN-SBIRT Curriculum contributed to advances in nursing student learning and engagement.

Other schools of nursing are encouraged to utilize the ATN-SBIRT Curriculum to address addiction education gaps and clinical skill needs in undergraduate programs. Some areas for improvement based on the preliminary results of student satisfaction surveys, student and faculty focus groups, and key informant interviews with clinical faculty suggest having more time and opportunities to practice both in real-life and practice settings (i.e., role plays and simulations). Other schools of nursing may want to consider extending the start-up period with the faculty and clinical preceptors prior to fully implementing the curriculum with the students. A lengthened start-up period may result in an increase in faculty knowledge about the addictions content and educational materials, thereby giving the faculty time to develop practice opportunities for students within clinical rotations and real-life settings.

Recently, IRETA and the University of Pittsburgh School of Nursing were approached by two other schools of nursing from the southern and northeastern regions of the United States requesting information about the ATN-SBIRT Curriculum. Members of the partnership team have presented at several conferences, poster sessions and national meetings to provide an overview of the project and the preliminary results from the data collected. Reactions to the project and resulting curriculum have been positive, suggesting that other schools of nursing and health care agencies may want to incorporate the ATN-SBIRT Curriculum into their undergraduate programs.

Providing addictions training for nurses, who constitute one of the largest health care provider groups, is essential in complex health systems. Enhancement of the assessment skills of nurses who work with patients in a variety of settings contribute to the efforts to treat the worldwide problem of substance misuse and abuse through screening, brief intervention, and referral to treatment. The described academic-community partnership increased the number of nurses prepared to assess for and intervene with this underserved, and often stigmatized, patient population. 


\section{Conflicts of interest}

The authors of this manuscript have no competing or conflicts of interest.

\section{Acknowledgements and funding}

Funding for the ATN-SBIRT Project was made possible by Grant D11HP14629 Nurse Education, Practice, and Retention Program from the Health Resources and Services Administration (HRSA), Department of Health and Human Services (DHHS).

\section{References}

[1] Madras, B.K., Compton, W.M., Avula, D., Stegbauer, T., Stein, J.B., Clark, H.W. Screening, brief interventions, referral to treatment (SBIRT) for illicit drug and alcohol use at multiple healthcare sites: Comparison at intake and 6 months later. Drug and Drug Dependence. 2009; 99(1-3): 280-295. PMid:18929451 http://dx.doi.org/10.1016/j.drugalcdep.2008.08.003

[2] Hyman, Z. Historical interpretations of alcohol use and misuse: implications for nursing curricula. Journal of Psychosocial Nursing and Mental Health Services. 2004; 42(11): 46-55.

[3] International Nurses Society on Addictions: Scope and standards of addictions nursing practice. American Nurses Association: Washington, DC. 2004.

[4] Mills, M.E., Jenkins, L.S. \& Waltz, C.F. Emphasis courses: preparing baccalaureate students for transition to the workforce. Journal of Professional Nursing. 2000; 16(5): 300-306. PMid:11033940 http://dx.doi.org/10.1053/jpnu.2000.9457

[5] Annapolis Coalition on the Behavioral Health Workforce. An Action Plan for Behavioral Health Workforce Development. Rockville, MD: Substance Abuse and Mental Health Services Administration. 2007.

[6] American Nurses Association (ANA). 2002. Nursing's agenda for the future [Internet]. Available from: https://www.ncsbn.org/Plan.pdf(Retrieved on January 14, 2011)

[7] Brady-Schwartz, D.C. Further evidence on the magnet recognition program: implications for nursing leaders. Journal of Nursing Administration. 2005; 35(9): 397-403. PMid:16200007

[8] Giddens, J., Brady, D., Brown, P., Wright, M., Smith, D., Harris, J. A new curriculum for a new era of nursing education. Nursing Education Perspectives. 2008; 29(4): 200-204. PMid:18770947

[9] Crow, S.M., Hartman, S.J. Nurse attrition as a process. Health Care Manager. 2005; 24(3): 276-283.

[10] Naegle, M. Nursing education in the prevention and treatment of SUD. In Haack, M.R. and Adger, H. (eds.). Strategic Plan for Interdisciplinary Faculty Development: Arming the Nation's Health Professional Workforce for a New Approach to Substance Use Disorders. SUABE7 23(3S). Kulwer Academic/Plenum Publishers. 2002.

[11] Howard, M.O., Walker, R.D., Walker, P.S., Suchinsky, R.T. Alcohol and drug education in schools of nursing. Journal of Alcohol and Drug Education. 1997; 42(3): 54-80.

[12] O’Neil, E., Krauel, P. Building transformational partnerships in nursing. Journal of Professional Nursing. 2004; 20 : $295-299$. http://dx.doi.org/10.1016/j.profnurs.2004.07.006

[13] Substance Abuse and Mental Health Services Administration. Results from the 2010 National Survey on Drug Use and Health: Summary of National Findings, NSDUH Series H-41, HHS Publication No. (SMA) 11-4658. Rockville, MD: Substance Abuse and Mental Health Services Administration. 2011.

[14] Humphreys K, McLellan, AT. Brief intervention, treatment, and recovery support services for Americans who have substance use disorders: An overview of policy in the Obama administration. Psychol Serv. 2010; 7: 275-284.

http://dx.doi.org/10.1037/a0020390

[15] Schneider Institute for Health Policy, Brandeis University. Substance Abuse: The Nation's Number One Health Problem. Princeton, N.J.: The Robert Wood Johnson Foundation. 2001.

[16] Ozechowski, T.J. Waldron, H.B. Assertive outreach strategies for narrowing the adolescent substance abuse treatment gap: Implications for research, practice, and policy. Journal of Behavioral Health Services \& Research. 2008; 37(1): 40-63. PMid:11571778 http: //dx.doi.org/ 10.1007/s11414-008-9136-0

[17] World Health Organization. Atlas on substance use: Resources for the prevention and treatment of substance use disorders. 2010.

[18] Murray, C.J.L., Lopez, A.D. The Global Burden of Disease in 1990: Final Results and Their Sensitivity to Epidemiological Perspectives, Discount Rates, Age-Weights and Disability Weights. In Murray, C.J.L. and Lopez, A.D. eds. The Global Burden of Disease: A Comprehensive Assessment of Mortality and Disability from Diseases, Injuries and Risk Factors in 1990 and Projected 
to 2020. Cambridge, MA: The Harvard School of Public health on Behalf of the World Health Organization and the World Bank. 1996; 247-293.

[19] Keller, P. S., Cummings, E. M., Davies, P. T. The role of marital discord and parenting in relations between parental problem drinking and child adjustment. Journal of Child Psychology and Psychiatry. 2005; 46: 943-951. PMid:16108997 http://dx.doi.org/10.1111/j.1469-7610.2004.00399.x

[20] Burns B.J., Phillips, S.D., Wagner, H.R., Barth, R.P., Kolko, D.J., Campbell, Y., et al. Mental health need and access to mental health services by youth involved with child welfare: A national survey. Journal of the American Academy of Child and Adolescent Psychiatry. 2004; 43: 960-970. http://dx.doi.org/10.1097/01.chi.0000127590.95585.65

[21] Mumola, C.J., Karberg, J.C. Drug use and dependence, state and federal prisoners, 2004. Washington, DC: US Department of Justice, Office of Justice Programs, Bureau of Justice Statistics. 2006.

[22] Substance Abuse and Mental Health Services Administration, Center for Behavioral Health Statistics and Quality. The TEDS Report: Length of Time from First Use to Adult Treatment Admission, Rockville, MD. 2011.

[23] Healthy People 2020. United States Department of Health and Human Services. 2011. Available from: http://www.healthypeople.gov/2020/about/default.aspx

[24] Institute of Medicine (IOM). Improving the quality of healthcare for mental health and substance-use conditions. Washington, DC: The National Academies Press. 2006.

[25] Bernstein E, Bernstein J, Feldman J, Fernandez W, Hagan M, Mitchell P, et al. An evidence based alcohol screening, brief intervention and referral to treatment (SBIRT) curriculum for emergency department (ED) providers improves skills and utilization. Substance Abuse. 2007; 28(4): 79-92. PMid:18077305 http://dx.doi.org/10.1300/J465v28n04_01. Available from: http://ovidsp.ovid.com/ovidweb.cgi?T=JS\&PAGE=reference \&D=medl\&NEWS=N\&AN=18077305.

[26] Academic ED SBIRT Research Collaborative: The impact of screening, brief intervention and referral for treatment in emergency department patients' alcohol use: A 3-, 6- and 12-month follow-up. Alcohol and Alcoholism. 2010; 45: 514-519. PMid:20876217 http://dx.doi.org/10.1093/alcalc/agq058

[27] Chudnofsky, C.R. Hazardous Use and Addictions: The Screening, Brief Intervention and Referral to Treatment Program (SBIRT). Presented at the Workshop on Hazardous Use and Addiction: The Screening Brief Intervention and Referral to Treatment Program Pittsburgh, Pennsylvania. 2007.

[28] Cuijpers, P., Riper, H., Lemmers, L. The effects on mortality of brief interventions for problem drinking: a meta-analysis. Addiction. 2004; 99(7): 839-845. PMid:15200579 http://dx.doi.org/10.1111/j.1360-0443.2004.00778.x

[29] Erickson, L.K. The scope for the problem and the case for screening, brief intervention, and referral to treatment. Counter Details: Alcohol use disorders in the primary care setting. 2008; 1-2.

[30] Ettner, S.L., Huang, D., Evans, E., Ash, D.R., Hardy, M., Jourabchi, M., et al. Benefit-cost in the California Treatment Outcome Project: does substance abuse treatment “pay for itself’’? Health Services Research. 2006; 41(1): 192-213. PMid:16430607 http://dx.doi.org/10.1111/j.1475-6773.2005.00466.x

[31] Fleming MF, Mundt MP, French MT, Manwell LB, Stauffacher EA \& Barry KL. Brief physician advice for problem drinkers: long-term efficacy and benefit-cost analysis. Alcoholism: Clinical \& Experimental Research. 2002; 26(1): 36-43.

http://dx.doi.org/10.1111/j.1530-0277.2002.tb02429.x

[32] Gentilello, L.M., Rivara, F.P., Donovan, D.M., Jurkovich, G.J., Daranciang, E., Dunn, C.W., et al. Alcohol intervention in a trauma center to reduce injury recurrence, Annals of Surgery. 1999; 230: 473-483. PMid:10522717 http://dx.doi.org/10.1097/00000658-199910000-00003

[33] Wells-Parker, E., Williams, M. Enhancing the effectiveness of traditional intervention with drinking drivers by adding brief individual intervention components. Social Science Research. 2002; 63: 655-664.

[34] Aalto, M., Saksanen, R., Laine, P., Forsström, R., Railaa, M., Kiviluoto, M., et al. Brief intervention for female heavy drinkers in routine general practice: a 3-year randomized controlled study. Alcoholism: Clinical \& Experimental Research. 2000; 24: 1680-1686. http://dx.doi.org/10.1111/j.1530-0277.2000.tb01969.x

[35] Aalto, M., Seppä, K., Mattila, P., Mustonen, H., Ruuth, K., Hyvärinen, H., et al. Brief intervention for male heavy drinkers in routine general practice: a three-year randomized controlled trial. Alcohol and Alcoholism. 2001; 36: 224-230. PMid:11373259

[36] Nilssen, O.D.D. Long-term effect of brief intervention in at-risk alcohol drinkers: a 9-year follow-up study. Alcohol and Alcoholism. 2004; 39(6): 548-551. PMid:15381513 http://dx.doi.org/10.1093/alcalc/agh095

[37] Wutzke, S.E., Conigrave, K.M., Saunders, J.B. \& Hall, W.D. The long-term effectiveness of brief interventions for unsafe alcohol consumption: a 10-year follow-up. Addiction. 2002; 97: 665-675. PMid:12084136 http://dx.doi.org/10.1046/j.1360-0443.2002.00080.x

[38] Substance Abuse and Mental Health Services Administration. 2011. Screening, Brief Intervention, and Referral to Treatment (SBIRT). Available from: http://www.samhsa.gov/prevention/SBIRT/index.aspx 
[39] Murray, M.M., Li, T.K. Expanding the role of the generalist nurse in the prevention and treatment of alcohol use disorders. Journal of Addictions Nursing. 2007; 18: 163-165. http://dx.doi.org/10.1080/10884600701699495

[40] Broyles, L. M., Gordon, A. J. SBIRT implementation: Moving beyond the interdisciplinary rhetoric. Substance Abuse. 2010; 31(4): 221-223. PMid:21038175 http://dx.doi.org/10.1080/08897077.2010.514238

[41] Kanter, R. Collaborative advantage: the art of alliances. Harvard Business Review. 1994; 72(4): 142-149.

[42] Center for Substance Abuse Treatment. Addiction Counseling Competencies: The Knowledge, Skills, and Attitudes of Professional Practice. Technical Assistance Publication (TAP) Series 21. DHHS Publication No. (SMA) 08-4171. Rockville, MD: Substance Abuse and Mental Health Services Administration, 2006, reprinted 2007 and 2008.

[43] International Nurses Society on Addictions. Scope and Standards of Addictions Nursing Practice. Washington, DC: The American Nurses Association. 2004.

[44] Murray, M.M., Savage, C. The NIAAA BSN nursing education curriculum: A rationale and overview. Journal of Addictions Nursing. 2010; 21: 3-5. http://dx.doi.org/10.3109/10884601003594488

[45] International Nurses Society on Addictions. The Core Curriculum of Addictions Nursing. Raleigh, NC: International Nurses Society on Addictions. 2006.

[46] Addiction Technology Transfer Center Network. The change book: A blueprint for technology transfer (2nd Ed.). Kansas City, MO: Author. 2004.

[47] Bandura, A. Social Learning Theory. New York: General Learning Press. 1977.

[48] Simpson, D. D. A conceptual framework for transferring research to practice. Journal of Substance Abuse Treatment. 2002; 22: 171-182. http://dx.doi.org/10.1016/S0740-5472(02)00231-3

[49] Miller, W. R., Yahne, C. E., Moyers, T. B., Martinez, J., Pirritano, M. A randomized trial of methods to help clinicians learn motivational interviewing. Journal of Consulting and Clinical Psychology. 2004; 72: 1050-1062. PMid:15612851 http://dx.doi.org/10.1037/0022-006X.72.6.1050

[50] Schoenwald, S. K., Henggeler, S. W. A public health perspective on the transport of evidence-based practices. Clinical Psychology: Science and Practice. 2004; 11: 360-363. http://dx.doi.org/10.1093/clipsy.bph092

[51] Sholomskas, D. E., Syracuse-Siewert, G., Rounsaville, B. J., Ball, S. A., Nuro, K. F., Carroll, K. M. We don't train in vain: A dissemination trial of three strategies of training clinicians in cognitive-behavioral therapy. Journal of Consulting and Clinical Psychology. 2005; 73: 106-115. PMid:15709837 http://dx.doi.org/10.1037/0022-006X.73.1.106

[52] Bahn, D. Social learning theory: Its application in the context of nurse education. Nurse Education Today. 2001; 21: 110-117. PMid:11170797 http://dx.doi.org/10.1054/nedt.2000.0522

[53] Kramer, M., Polifroni, E.C., Organek, N. Effects of faculty practice on student learning outcomes. Journal of Professional Nursing. 1986; 2(5): 289-301. http://dx.doi.org/10.1016/S8755-7223(86)80029-1

[54] Murphy, E.M. Promoting Healthy Behavior. Health Bulletin 2. Washington, DC: Population Reference Bureau. 2005.

[55] Quinn, F. The Principles and Practice of Nurse Education, 2nd ed. London: Chapman and Hall. 1991.

[56] American Nurses Association. Psychiatric-Mental Health Nursing: Scope and Standards of Practice. Silver Spring, MD: The American Nurses Association. 2007. 